\title{
Bufalin reverses intrinsic and acquired drug resistance to cisplatin through the AKT signaling pathway in gastric cancer cells
}

\author{
HONGYAN ZHAO ${ }^{1,2}$, DALI ZHAO ${ }^{3}$, HUILIN JIN ${ }^{2}$, HONGWEI LI ${ }^{2}$, \\ XIAOYING YANG ${ }^{2}$, LIWEI ZHUANG ${ }^{1}$ and TIEFU LIU ${ }^{1}$ \\ ${ }^{1}$ Department of Gastroenterology, The Fourth Affiliated Hospital of Harbin Medical University, Harbin, Heilongjiang 150001; \\ ${ }^{2}$ Department of Gastroenterology, The Fourth Hospital of Harbin, Harbin, Heilongjiang 150026; \\ ${ }^{3}$ Department of General Surgery, The First Affiliated Hospital of Harbin Medical University, \\ Harbin, Heilongjiang 150001, P.R. China
}

Received March 1, 2015; Accepted April 7, 2016

DOI: $10.3892 / \mathrm{mmr} .2016 .5426$

\begin{abstract}
Cisplatin is the most common chemotherapeutic agent for gastric cancer (GC), however it activates AKT, which contributes to intrinsic and acquired resistance. Bufalin, a traditional Chinese medicine, shows significant anticancer activity by inhibiting the AKT pathway. It was therefore hypothesized that bufalin could counteract cisplatin resistance in GC cells. SGC7901, MKN-45 and BGC823 human GC cells were cultured under normoxic and hypoxic conditions. Effects of cisplatin and bufalin on GC cells were measured by a cell counting kit, apoptosis was analyzed by flow cytometry, and immunoblotting was used to detect proteins associated with the AKT signaling pathway. It was demonstrated that bufalin synergized with cisplatin to inhibit proliferation and promote apoptosis of GC cells by diminishing the activation of cisplatin-induced AKT under normoxic and hypoxic conditions. Bufalin also inhibits cisplatin-activated molecules downstream of AKT that affect proliferation and apoptosis, including glycogen synthase kinase, mammalian target of rapamycin, ribosomal protein S6 Kinase and eukaryotic translation initiation factor-4E-binding protein-1. To investigate acquired cisplatin resistance, a cisplatin-resistant cell line SGC7901-CR was used. It was demonstrated that bufalin reversed acquired cisplatin resistance and significantly induced apoptosis through the AKT pathway. These results imply that bufalin could extend the therapeutic effect of cisplatin on GC cells when administered in combination.
\end{abstract}

Correspondence to: Mrs. Liwei Zhuang or Mrs. Hongyan Zhao, Department of Gastroenterology, The Fourth Affiliated Hospital of Harbin Medical University, 37 Yi Yuan Street, Harbin, Heilongjiang 150001, P.R. China

E-mail: zhuangliweiyd@126.com

E-mail: liutiefu2014@sina.com

Key words: bufalin, gastric cancer, drug resistance, cisplatin, AKT

\section{Introduction}

Gastric cancer (GC) is the fifth most common type of malignancy worldwide and is the third leading cause of cancer-related mortality (1). Worldwide, $70 \%$ of GC cases occur in developing countries and half in Eastern Asia, predominantly in China (1). As the majority of GC cases are clinically advanced at diagnosis, surgery is no longer possible, thus chemotherapy is essential (2). Cisplatin is the most common chemotherapeutic agent for GC (3). Although the combination of cisplatin and $\mathrm{S}-1$ is an established first-line chemotherapeutic strategy for advanced GC $(4,5)$, intrinsic and acquired resistance to cisplatin are major obstacles to effective treatment. Understanding the underlying mechanisms of cisplatin resistance in GC is critical to overcoming it.

The phosphatidylinositol 3-kinase (PI3K)/AKT signaling pathway regulates a number of aspects of cancer progression $(6,7)$ and is also considered to be a multidrug resistance locus in cancer (8). In GC, AKT and phosphorylated AKT (p-AKT) are detected in 74 and $78 \%$ of tumors, respectively (9). Overexpression of AKT decreases GC sensitivity to cisplatin $(10,11)$. AKT activation contributes to acquired cisplatin resistance in GC $(12,13)$. Hypoxia is another cause of GC resistance to cisplatin therapy (13-15). Cells in solid tumors are subjected to a range of low oxygen conditions and varying hypoxic intensities based on local oxygen diffusion (16). Hypoxia-inducible factor (HIF)- $1 \alpha$ is a fundamental driver of cellular adaptation to hypoxia $(14,17)$. Reportedly, the PI3K/AKT pathway activation upregulates HIF-1 $\alpha$ expression $(13,18,19)$, which contributes to cisplatin resistance in GC cells $(13,14)$. It was therefore suggested that AKT may be central to intrinsic and acquired cisplatin resistance in GC.

Bufalin, a traditional Chinese medicine, has been shown to exhibit anticancer activity (20). Our previous study demonstrated that bufalin markedly inhibits proliferation and promotes apoptosis through endoplasmic reticulum stress in hepatocellular carcinoma cells (21). Experimental studies have shown that bufalin affects cancer cells by inhibiting the AKT pathway (22-25). The present study demonstrated that intrinsic and acquired resistance to cisplatin can be diminished by bufalin, which affects the AKT pathway in GC cells. 


\section{Materials and methods}

Cell culture. SGC7901, MKN-45 and BGC823 human GC cells were obtained from the Chinese Academy of Sciences Cell Bank (Shanghai, China). The cells were routinely cultured in RPMI-1640 medium (Sigma-Aldrich, St. Louis, MO, USA) supplemented with $10 \%$ fetal calf serum (Sigma-Aldrich) at $37^{\circ} \mathrm{C}$ in a humidified atmosphere of $5 \% \mathrm{CO}_{2}$. To induce hypoxia, cells were incubated in a hypoxia chamber containing $1 \% \mathrm{O}_{2}, 5 \% \mathrm{CO}_{2}$ and $94 \% \mathrm{~N}_{2}$ at $37^{\circ} \mathrm{C}$.

Antibodies and reagents. The rabbit anti-human monoclonal antibodies (Abs) against AKT (\#2920; 1:2,000), p-AKT (Ser473; \#4060; 1:2,000), glycogen synthase kinase (GSK)-3 $\beta$ (\#12456; 1:1,000), phosphorylated GSK3 $\beta$ (p-GSK3 $\beta$; Ser9; \#5558; 1:1,000), mammalian target of rapamycin (mTOR; \#2983; 1:1,000), phosphorylated mTOR (p-mTOR; Ser2448; \#5536; 1:1,000), eukaryotic translation initiation factor 4E binding protein 1 (4EBP1; \#9644; 1:1,000), phosphorylated 4EBP1 (P-4EBP1; Ser65; \#9451; 1:1,000), ribosomal protein S6 kinase (S6K; \#5707; 1:1,000) and phosphorylated S6K (p-S6K; Thr389; \#9206; 1:1,000) were obtained from Cell Signaling Technology, Inc. (Shanghai, China). Anti- $\beta$-actin (mouse IgG1; sc-47778; 1:2,000) and anti-HIF-1 $\alpha$ (rabbit IgG; sc-10790; 1:500) were obtained from Santa Cruz Biotechnology, Inc. (Santa Cruz, CA, USA). Cisplatin and bufalin were purchased from Sigma-Aldrich. GDC0068 and Fumonisin B1 were from Santa Cruz Biotechnology, Inc. The reagents were dissolved in $100 \%$ dimethyl sulfoxide (DMSO; Sigma-Aldrich) and were diluted with Dulbecco's modified Eagle's medium (Sigma-Aldrich) to the desired concentrations; all concentrations contained a final DMSO concentration of less than $0.1 \%$.

Establishment of SGC7901 cisplatin-resistant cells. SGC7901 cisplatin-resistant cells were developed by continuous exposure to cisplatin starting at $0.5 \mu \mathrm{M}$ and increasing in a stepwise manner to $5 \mu \mathrm{M}$. Cells that were able to survive in the medium containing $5 \mu \mathrm{M}$ cisplatin were considered to be cisplatin-resistant and termed SGC7901-CR $(13,26)$.

Cell viability and apoptosis assays. SGC7901, MKN-45, BGC823 cells were randomly divided into different groups. Each group of cells was cultured under normoxic or hypoxic conditions, then were treated with $0,50,100$ or $200 \mathrm{nmol} / 1$ bufalin for $48 \mathrm{~h}$, or were treated with $0.10 \mu \mathrm{M}$ cisplatin and/or $0.100 \mathrm{nM}$ bufalin for $48 \mathrm{~h}$. SGC7901 cells were treated with $5 \mu \mathrm{M}$ GDC0068 and/or $10 \mu \mathrm{M}$ Fumonisin B1 for $6 \mathrm{~h}$, then were treated with $0.10 \mu \mathrm{M}$ cisplatin and/or $0.100 \mathrm{nM}$ bufalin under normoxic or hypoxic conditions for $48 \mathrm{~h}$ and were then harvested. Cell viability was measured with a Cell Counting kit-8 (CCK-8) kit (Dojindo Molecular Technologies, Inc., Gaithersburg, MD, USA), followed by the addition of $10 \mu \mathrm{l}$ CCK-8 solution. The cells were then incubated for $2 \mathrm{~h}$ at $37^{\circ} \mathrm{C}$, then optical density was read at $450 \mathrm{~nm}$. All experiments were performed in triplicate. Apoptosis was analyzed by flow cytometry as previously described $(21,27)$. In brief, cells were seeded at a density of $15 \times 10^{5}$ cells/well in 6-well plates, cultured with different reagents for $48 \mathrm{~h}$ and harvested. Cells were washed with phosphate-buffered saline and then stained with $5 \mu \mathrm{l}$ Annexin $\mathrm{V}$ and $5 \mu \mathrm{l}$ propidium iodide for
$15 \mathrm{~min}$ in the dark at room temperature according to the manufacturers instructions (BD Biosciences, San Jose, CA, USA). The apoptotic rate (\%) of the stained cells was analyzed using an Epics Altra II flow cytometer (Beckman Coulter, Inc., Brea, CA, USA). Experiments were repeated three times.

Immunoblotting. Protein concentrations of cell lysates were determined using the Bio-Rad protein assay (Bio-Rad, Richmond, CA, USA). Lysates were resolved by sodium dodecyl sulfate-polyacrylamide gel electrophoresis; proteins were transferred to membranes and immunoblotted as previously described $(21,27)$ In brief, cells were treated with different reagents for $48 \mathrm{~h}$, then lysed in lysis buffer [2\% sodium dodecyl sulfate (SDS), $10 \%$ glycerol, $62.5 \mathrm{mM}$ Tris- $\mathrm{HCl}, \mathrm{pH}$ 6.8]. Equal amounts of cell lysate $(20 \mu \mathrm{g})$ were resolved on SDS-polyacrylamide gels, and the proteins were transferred to a nitrocellulose membrane. The membrane was blocked with $10 \%$ non-fat milk in Tris-buffered saline containing $0.1 \%$ (v/v) Tween-20 for $50 \mathrm{~min}$ and then incubated again with $10 \%$ non-fat milk containing the primary antibodies for $2 \mathrm{~h}$ at room temperature. Subsequent to washing, the membrane was incubated with $10 \%$ non-fat milk containing the secondary antibodies conjugated with horseradish peroxidase for $1 \mathrm{~h}$ at room temperature. The proteins were visualized with 5-bromo-4-chloro-3-indolyl phosphate/nitro blue tetrazolium (Tiangen Biotech Co., Ltd., Beijing, China). Blots were stained with the anti- $\beta$-actin antibody, the relative level (\%) of each protein was normalized to the $\beta$-actin band density, and were evaluated using ImageJ software, version 1.46 (National Institutes of Health, Bethesda, MD, USA).

Statistical analysis. All data are expressed as the mean \pm standard deviation. Comparisons were made using one-way analysis of variance followed by Dunnett's t-test. Statistical comparisons were performed using SPSS software, version 13.0 (SPSS, Inc., Chicago, IL, USA). P $<0.05$ was considered to indicate a statistically significant difference.

\section{Results}

Cisplatin- and hypoxia-induced AKT activation contributes to cisplatin resistance in GC cells. The effects of cisplatin and/or hypoxia on AKT expression and activation in GC cells were investigated. As predicted, SGC7901, MKN-45 and BGC 823 cells treated with cisplatin or cultured under hypoxia had increased p-AKT levels when compared with cells in normoxic conditions. When cells were treated with cisplatin under hypoxia, the p-AKT levels were increased compared with that of cells treated with cisplatin or hypoxia alone (Fig. 1A). Levels of total AKT were not significantly altered by either cisplatin or hypoxia in the three cell lines (Fig. 1A).

To investigate the exact role of AKT activation in cisplatin resistance, GDC0068 (a specific AKT inhibitor) and Fumonisin B1 (a specific AKT activator) was introduced to SGC7901 cells. The antiproliferation effect of cisplatin was significantly facilitated by GDC0068 and attenuated by Fumonisin B1 in SGC7901 cells, under normoxic and hypoxic conditions (Fig. 1B). Consistent with these results, cisplatin-induced apoptosis rates were also significantly 
A
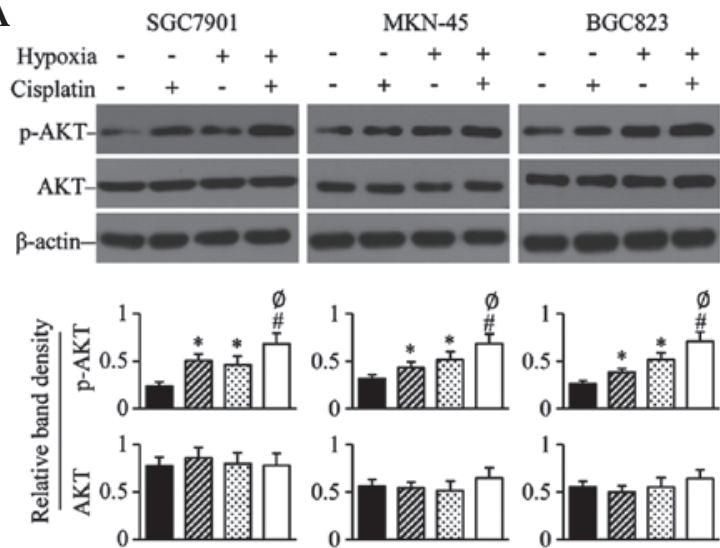

C

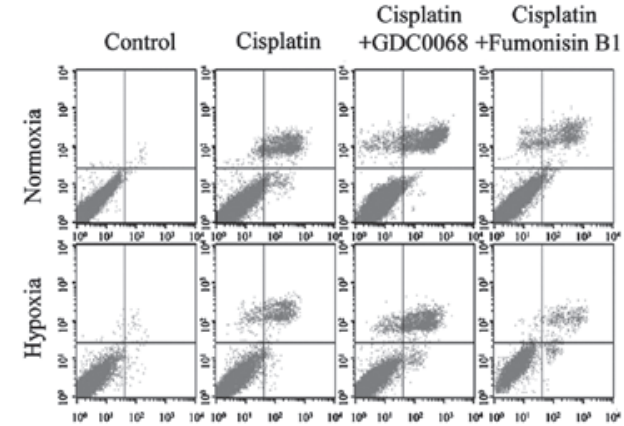

B

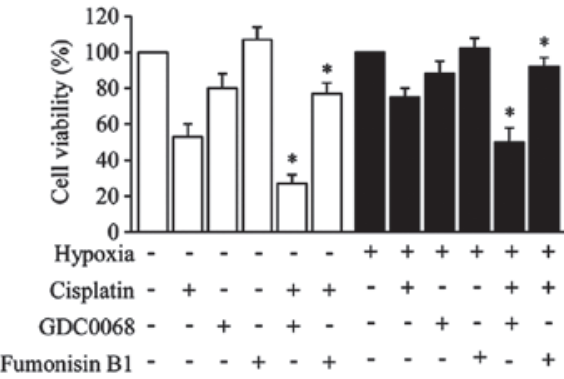

D

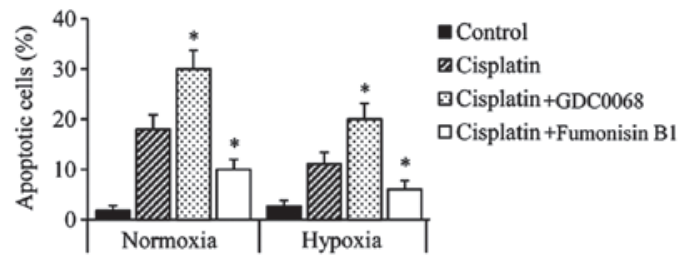

Figure 1. AKT activation and cisplatin resistance in gastric cancer cells. (A) Gastric cancer cell lines were treated with $0 \mu \mathrm{M}$ (control) or $10 \mu \mathrm{M}$ cisplatin under normoxic or hypoxic conditions for $48 \mathrm{~h}$. Cell lysates were immunoblotted and the density of each band was measured. Band densities of p-AKT and AKT were normalized to $\beta$-actin. ${ }^{*} \mathrm{P}<0.05$ compared with untreated cells. ${ }^{*} \mathrm{P}<0.05$ compared with cells treated with cisplatin. ${ }^{\Phi} \mathrm{P}<0.05$ compared with cells cultured under hypoxia. SGC7901 cells were treated with or without $10 \mu \mathrm{M}$ cisplatin and/or GDC0068 (5 $\mu \mathrm{M})$ and/or Fumonisin B1 (10 $\mu \mathrm{M})$ under normoxic or hypoxic conditions for $48 \mathrm{~h}$. (B) Cell viability was measured. (C) Flow cytometry was used to analyze apoptosis and (D) data were quantified. "P<0.05 compared with cells treated with cisplatin. p-, phosphorylated.

increased by GDC0068 and attenuated by Fumonisin B1 in SGC7901 cells, in normoxic and hypoxic conditions (Fig. 1C and D). In addition, it was demonstrated that the efficiency of cisplatin in SGC7901 cells was significantly limited by hypoxia (Fig. 1B-D).

Bufalin synergizes with cisplatin to inhibit growth and induce apoptosis in GC cells. To investigate the effect of bufalin on AKT activation in GC cells, SGC7901, MKN-45 and BGC823 cells were exposed to varying doses of bufalin under normoxic or hypoxic conditions. Bufalin significantly downregulated p-AKT levels in a dose-dependent manner, but did not significantly alter AKT levels under either normoxia or hypoxia (Fig. 2A). The combined effect of bufalin and cisplatin was also investigated in GC cells. Bufalin synergistically enhanced the antiproliferation effect of cisplatin in normoxic or hypoxic conditions in the 3 GC cell lines (Fig. 2B). Similarly, cisplatin+bufalin significantly increased the number of apoptotic cells compared with the effect of cisplatin or bufalin alone under either normoxic or hypoxic conditions in SGC7901 cells (Fig. 2C and D).

Bufalin eradicates cisplatin-induced activation of the AKT pathway in SGC7901 cells. The mechanism underlying the anticancer effect of cisplatin+bufalin in SGC7901 cells was investigated. Cells treated with cisplatin exhibited markedly increased expression of p-AKT and its downstream molecules p-GSK3 $\beta$, p-mTOR, P-4EBP1 and p-S6K; whereas cells treated with bufalin exhibited significantly reduced expression of these five proteins in normoxic and hypoxic conditions, compared with untreated cells (Fig. 3).

Cisplatin-resistant GC cells show sensitivity to bufalin with active AKT pathways. To examine the contribution of the AKT pathway to acquired cisplatin resistance, SGC7901 cells were exposed to gradually increasing concentrations of cisplatin. After 6 months of culture, the resulting SGC7901-CR cells had recovered their proliferative capacity comparable to that of parental cells (Fig. 4A). However, the acquired resistance of SGC7901-CR cells was reversed by bufalin (Fig. 4B). Flow cytometry showed that bufalin induced a significant increase in the number of apoptotic SGC7901-CR cells compared with untreated controls (Fig. 4C and D). Although SGC7901-CR cells expressed higher levels of p-AKT, p-GSK3 $\beta, p-m T O R$, p-4EBP1 and p-S6K than their parental SGC7901 cells (Fig. 4E), SGC7901-CR cells treated with bufalin expressed significantly less of these five proteins than untreated SGC7901-CR cells (Fig. 4E).

\section{Discussion}

Cisplatin remains a common chemotherapeutic agent for GC (3). Unfortunately, intrinsic and acquired resistance to cisplatin is common. The present study demonstrated that activation of the AKT pathway contributes to intrinsic and acquired resistance to cisplatin, and blocking the AKT pathway with bufalin enhances the efficacy of cisplatin in GC cells. 

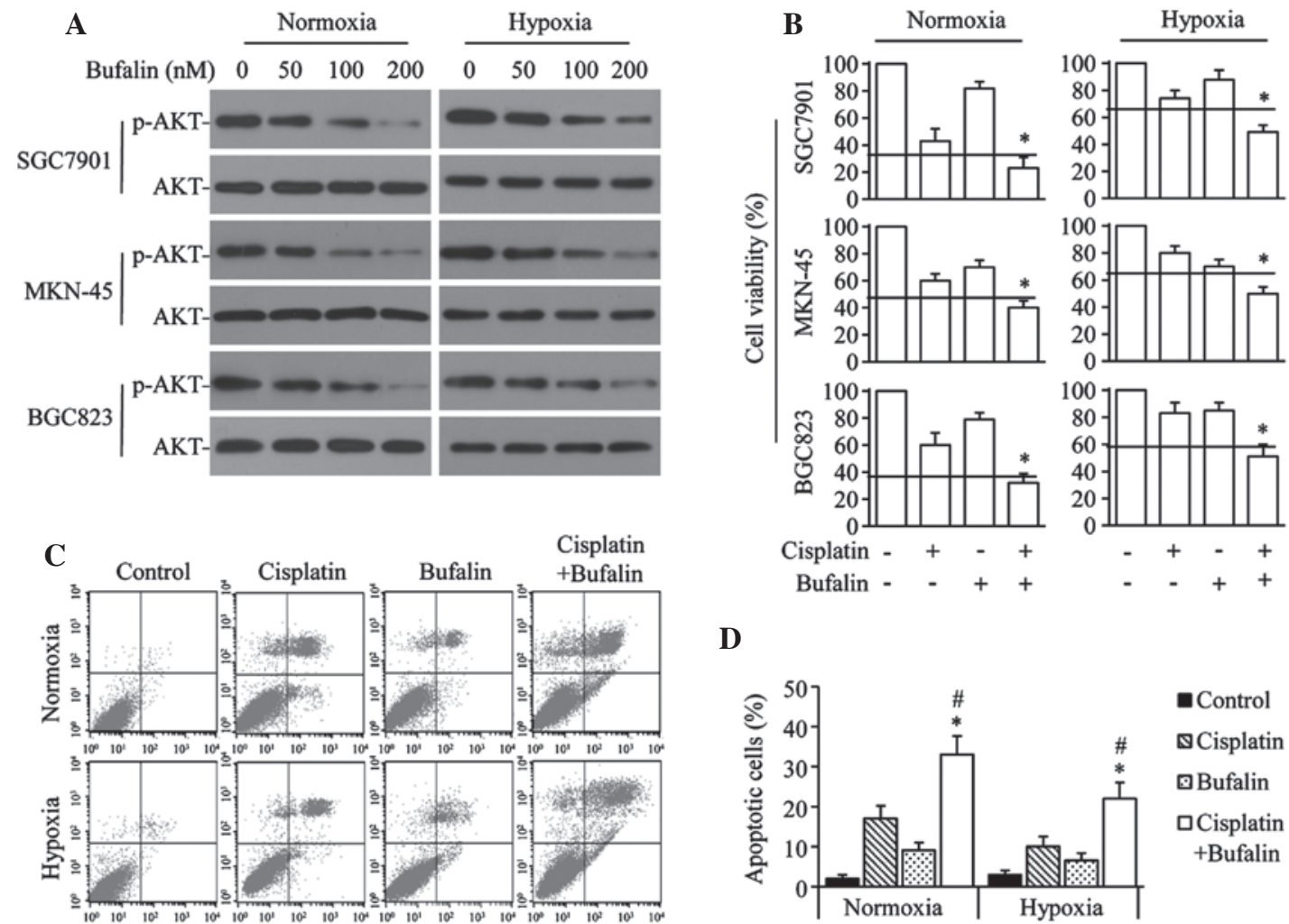

D

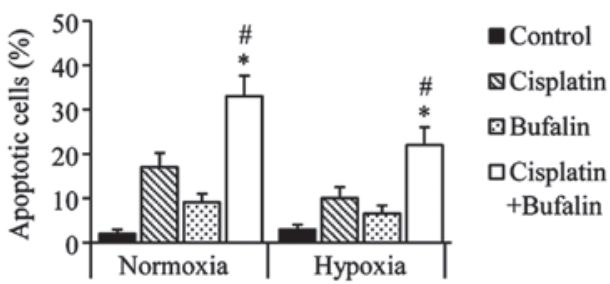

Figure 2. Synergistic effect of bufalin and cisplatin in gastric cancer cells. (A) Gastric cancer cells were treated without or with bufalin at different concentrations under normoxic or hypoxic conditions for $48 \mathrm{~h}$; cell lysates were then immunoblotted. (B) Gastric cancer cells were treated without or with cisplatin $(10 \mu \mathrm{M})$ and/or bufalin $(100 \mathrm{nM})$ under normoxic or hypoxic conditions for $48 \mathrm{~h}$; cell viability was then measured. Black lines: synergistic threshold. ${ }^{*} \mathrm{P}<0.05$ compared with cells treated with cisplatin only. SGC7901 cells were treated as in (B) and were subjected to flow cytometry for analyzing apoptosis. (C) Representative dot plots of SGC7901 cells subjected to flow cytometry to analyze apoptosis patterns. (D) Apoptosis rates. "P<0.05 compared with cells treated with cisplatin. ${ }^{*} \mathrm{P}<0.05$ compared with cells treated with bufalin. p-, phosphorylated.

Bufalin, a bioactive component of skin and parotid venom glands of the Venenum bufonis toad (20), has been tested in clinical trials to treat advanced hepatocellular carcinoma, non-small-cell lung cancer and pancreatic cancer (28); and has been shown experimentally to inhibit cancer through the AKT pathway (22-25). In the present study, bufalin inhibited the activation of AKT and its downstream molecules GSK-3 $\beta$, mTOR, S6K and 4EBP1; and when combined with cisplatin, inhibited proliferation and promoted apoptosis of GC cells by diminishing activation of the AKT y under normoxic and hypoxic conditions. Bufalin also reversed acquired cisplatin resistance and induced apoptosis in SGC7901-CR cells through the AKT pathway.

AKT is a member of a family of serine/threonine kinases and acts downstream of PI3K to phosphorylate various molecules involved in several cancer-related processes $(7,8,29)$. Activation of the ATK pathway is frequently implicated in resistance to anticancer therapies; thus, inhibitors of the AKT pathway are being evaluated in pre-clinical and clinical studies to determine whether they can restore sensitivity to combinations of therapeutic agents (7,30-32). Overexpression and activation of AKT has been shown to contribute to cisplatin resistance in GC cells (10-13). Cisplatin is generally considered a cytotoxic drug that kills cancer cells by damaging DNA, inhibiting DNA synthesis and mitosis, and inducing apoptosis (33). Cisplatin-induced DNA damage reportedly triggers PI3K/AKT activation, which in turn phosphorylates its downstream molecules and promotes survival of cancer cells $(34,35)$. The present study demonstrated that AKT activation causes intrinsic and acquired resistance to cisplatin in GC cells. p-AKT upregulates its downstream molecules p-GSK3 $\beta$, p-mTOR, P-4EBP1 and p-S6K. Treatment with a combination of bufalin and cisplatin inhibited p-AKT, and inhibited the growth and induced apoptosis of GC cells.

Another intrinsic cause of cisplatin resistance is the hypoxic microenvironment that commonly exists in solid tumors $(13,14,17)$. The aberrant microvasculature of solid tumors leads to deficient oxygen delivery in certain regions, creating zones of hypoxia (16). Thus, attacking normoxic and hypoxic cells, which are mixed within the tumors in different regions of differing oxygen partial pressures, is a reasonable strategy to treat solid cancers. The present study shows that hypoxic GC cells were refractory to cisplatin-induced growth inhibition and apoptosis and had high levels of p-AKT and its downstream molecules p-GSK3 $\beta$, p-mTOR, P-4EBP1 and p-S6K. Downregulation of p-AKT by treatment with bufalin significantly improved the efficacy of cisplatin in hypoxic GC cells. These data show that hypoxia induces cisplatin resistance at least partially by activating the AKT pathway. Hypoxia-induced AKT activation has been elucidated in a number of types of cancer (36). Reportedly, AKT activation increases expression of HIF-1 $\alpha(13,18,19)$, which in turn aggravates hypoxia. This indicates positive feedback, whereby 


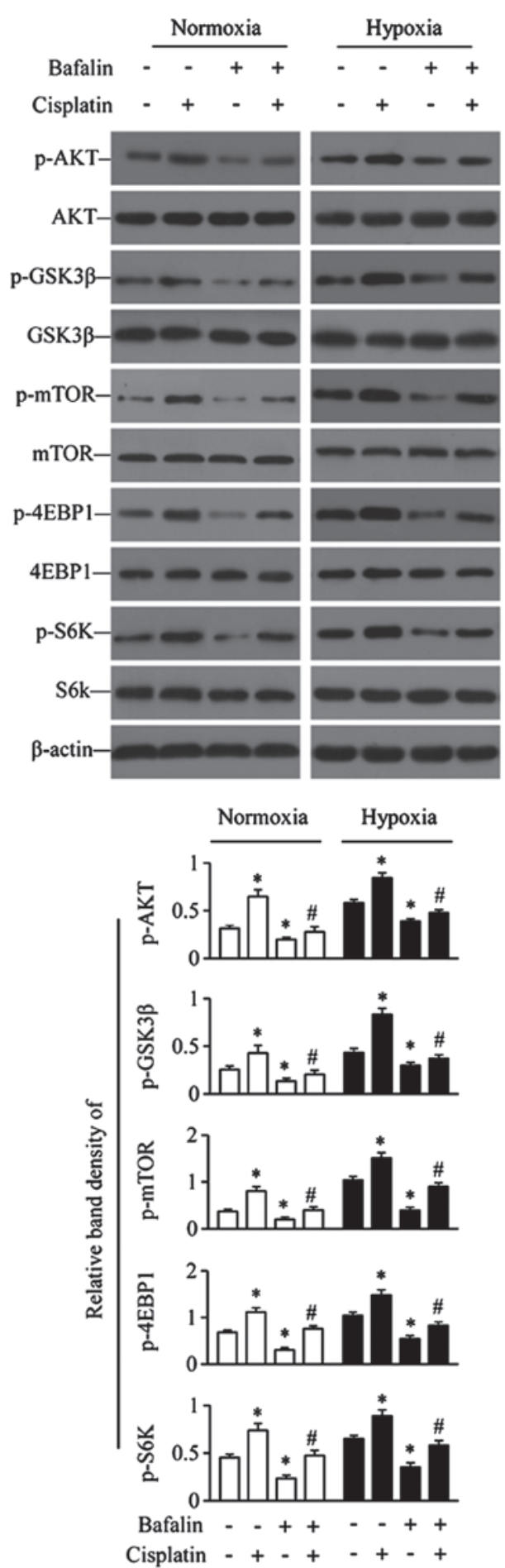

Figure 3. Bufalin potentiates the effects of cisplatin by inhibiting the AKT pathway. SGC7901 cells were treated without or with cisplatin $(10 \mu \mathrm{M})$ and/or bufalin $(100 \mathrm{nM})$ under normoxic or hypoxic conditions for $48 \mathrm{~h}$. Cell lysates were immunoblotted and the density of each band was measured. Band densities of p-AKT, p-GSK3 $\beta, \mathrm{p}-\mathrm{mTOR}, \mathrm{p}-4 \mathrm{EBP} 1$ and $\mathrm{p}$-S6K were normalized to the respective total form. ${ }^{*} \mathrm{P}<0.05$ compared with untreated cells. ${ }^{*} \mathrm{P}<0.05$ compared with cells treated with cisplatin. p-, phosphorylated; GSK, glycogen synthase; mTOR, mammalian target of rapamycin; 4EBP1, eukaryotic translation initiation factor $4 \mathrm{E}$ binding protein 1; S6K, ribosomal protein S6 kinase.

hypoxia is induced by p-AKT and HIF- $1 \alpha$, which increases cisplatin resistance. Thus breaking the cycle by inhibiting AKT is a reasonable strategy to overcome cisplatin resistance under hypoxia.
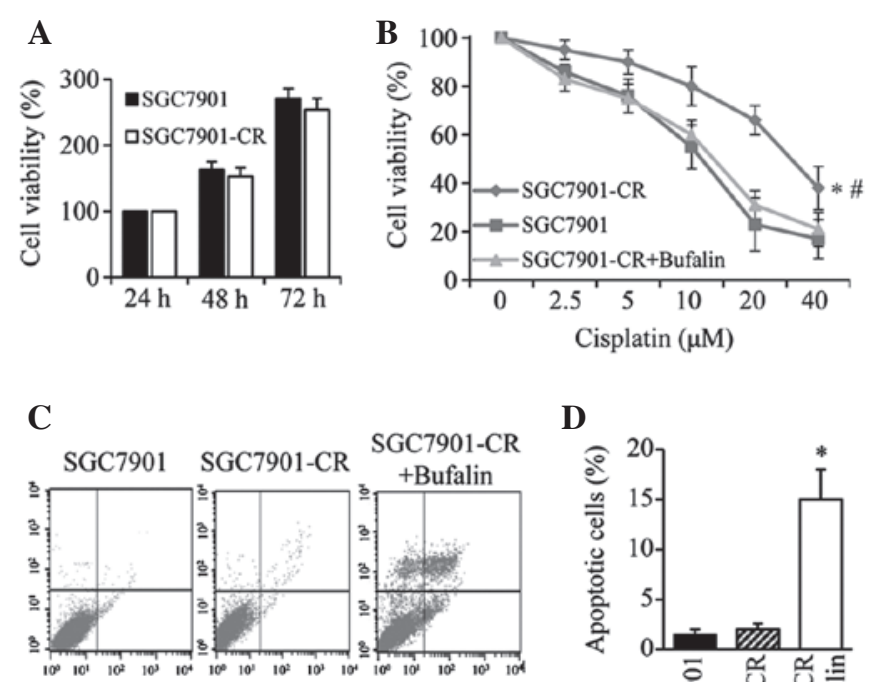

D

$\mathbf{E}$
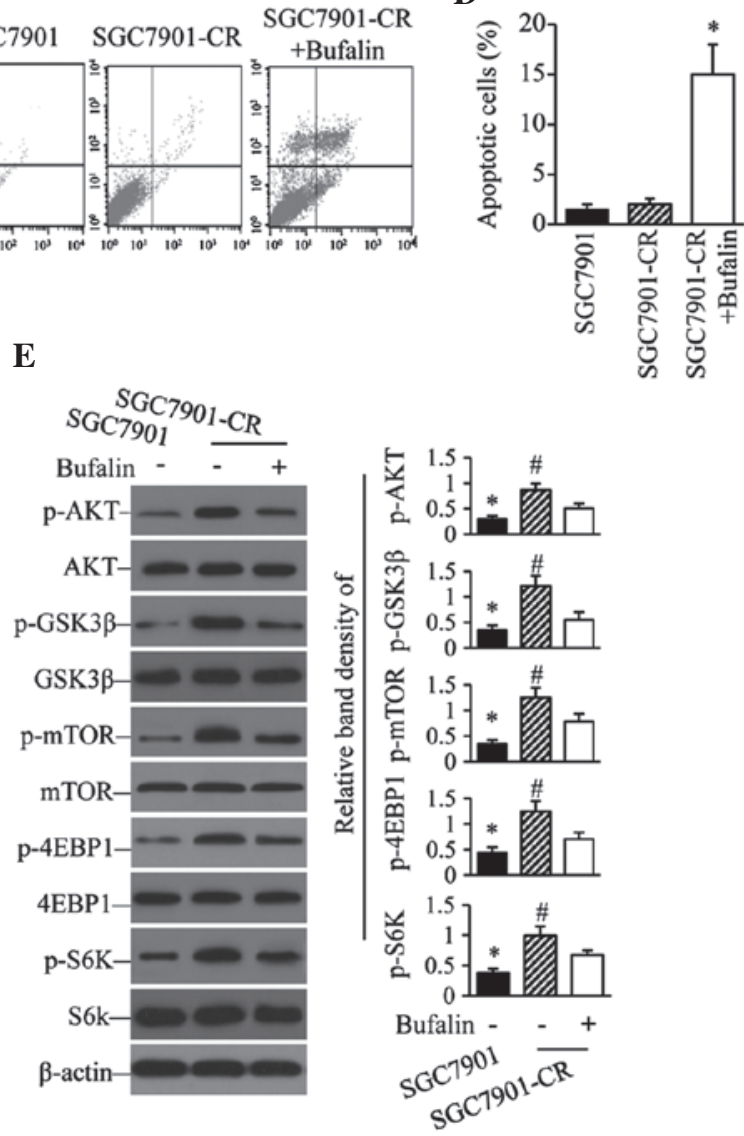

Figure 4. Activation of the AKT pathway contributes to acquired cisplatin resistance. (A) SGC7901 and SGC7901-CR cells were cultured for 24,48 or $72 \mathrm{~h}$; cell viability was then measured. (B) SGC7901 cells and SGC7901-CR cells treated without or with bufalin (100 nM) were cultured with indicated concentrations of cisplatin for $48 \mathrm{~h}$; cell viability was then measured. " $\mathrm{P}<0.05$ compared with SGC7901 cells. ${ }^{\text {"P }}<0.05$ compared with SGC7901CR + bufalin cells. SGC7901 cells and SGC7901-CR cells treated without or with bufalin $(100 \mathrm{nM})$ were cultured for $48 \mathrm{~h}$. Cells were subjected to flow cytometry to analyze apoptosis. (C) Representative dot plots are shown. (D) Apoptosis rates ${ }^{*} \mathrm{P}<0.05$ compared with SGC7901-CR cells. (E) Cell lysates were immunoblotted and the density of each band was measured. Band densities of p-AKT, p-GSK3 $\beta$, p-mTOR, P-4EBP1 and $\mathrm{p}$-S6K were normalized to the respective total form. "P<0.05 compared with untreated cells. "P<0.05 compared with cells treated with cisplatin. $C R$, cisplatin resistant; p-, phosphorylated; GSK, glycogen synthase; mTOR, mammalian target of rapamycin; 4EBP1, eukaryotic translation initiation factor $4 \mathrm{E}$ binding protein 1; S6K, ribosomal protein S6 kinase.

In conclusion, the present results indicate that administering cisplatin in combination with bufalin may overcome or delay resistance to cisplatin and extend the efficacy of cisplatin in treating GC, thus suggesting a novel strategy for treatment of advanced GC to be investigated further in clinical trials. 


\section{Acknowledgements}

This study was supported by Health Department of Heilongjiang Province of China (grant no. 2014-013).

\section{References}

1. Ferlay J, Soerjomataram I, Dikshit R, Eser S, Mathers C, Rebelo M, Parkin DM, Forman D and Bray F: Cancer incidence and mortality worldwide: Sources, methods and major patterns in GLOBOCAN 2012. Int J Cancer 136: E359-E386, 2015.

2. Shen L, Shan YS, Hu HM, Price TJ, Sirohi B, Yeh KH, Yang YH, Sano T, Yang HK, Zhang X, et al: Management of gastric cancer in Asia: Resource-stratified guidelines. Lancet Oncol 14: e535-e547, 2013.

3. Pasini F, Fraccon AP and DE Manzoni G: The role of chemotherapy in metastatic gastric cancer. Anticancer Res 31: 3543-3554, 2011.

4. Matt P, van Zwieten-Boot B, Calvo Rojas G, Ter Hofstede H, Garcia-Carbonero R, Camarero J, Abadie E and Pignatti F: The European medicines agency review of Tegafur/Gimeracil/ Oteracil (Teysuno ${ }^{\mathrm{TM}}$ ) for the treatment of advanced gastric cancer when given in combination with cisplatin: Summary of the scientific assessment of the committee for medicinal products for human use (CHMP). Oncologist 16: 1451-1457, 2011.

5. Okuno T, Shirotsuki J, Murahashi K and Sawada T: Advanced gastric cancer (stage IV) leading to perforation during chemotherapy with S-1 plus cisplatin. Gan To Kagaku Ryoho 41: 1313-1315, 2014 (In Japanese).

6. Sasaki T and Kuniyasu H: Significance of AKT in gastric cancer (Review). Int J Oncol 45: 2187-2192, 2014.

7. Polivka J Jr and Janku F: Molecular targets for cancer therapy in the PI3K/AKT/mTOR pathway. Pharmacol Ther 142: 164-175, 2014.

8. Radisavljevic Z: AKT as locus of cancer multidrug resistance and fragility. J Cell Physiol 228: 671-674, 2013.

9. Nam SY, Lee HS, Jung GA, Choi J, Cho SJ, Kim MK, Kim WH and Lee BL: Akt/PKB activation in gastric carcinomas correlates with clinicopathologic variables and prognosis. APMIS 111: 1105-1113, 2003.

10. Zhang LL, Zhang J, Shen L, Xu XM and Yu HG: Overexpression of AKT decreases the chemosensitivity of gastric cancer cells to cisplatin in vitro and in vivo. Mol Med Rep 7: 1387-1390, 2013.

11. Zhang J, Zhang LL, Shen L, Xu XM and Yu HG: Regulation of AKT gene expression by cisplatin. Oncol Lett 5: 756-760, 2013.

12. Park J, Ko YS, Yoon J, Kim MA, Park JW, Kim WH, Choi Y, $\mathrm{Kim} \mathrm{JH}, \mathrm{Cheon} \mathrm{Y}$ and Lee BL: The forkhead transcription factor FOXO1 mediates cisplatin resistance in gastric cancer cells by activating phosphoinositide 3-kinase/Akt pathway. Gastric Cancer 17: 423-430, 2014.

13. Sun XP, Dong X, Lin L, Jiang X, Wei Z, Zhai B, Sun B, Zhang Q, Wang X, Jiang $\mathrm{H}$, et al: Up-regulation of survivin by AKT and hypoxia-inducible factor $1 \alpha$ contributes to cisplatin resistance in gastric cancer. FEBS J 281: 115-128, 2014.

14. Rohwer N, Dame C, Haugstetter A, Wiedenmann B, Detjen K, Schmitt CA and Cramer T: Hypoxia-inducible factor lalpha determines gastric cancer chemosensitivity via modulation of p53 and NF-kappaB. PLoS One 5: e12038, 2010.

15. Adamski J, Price A, Dive C and Makin G: Hypoxia-induced cytotoxic drug resistance in osteosarcoma is independent of HIF-1alpha. PLoS One 8: e65304, 2013.

16. Wilson WR and Hay MP: Targeting hypoxia in cancer therapy. Nat Rev Cancer 11: 393-410, 2011.

17. Rankin EB and Giaccia AJ: The role of hypoxia-inducible factors in tumorigenesis. Cell Death Differ 15: 678-685, 2008.

18. Lee SH, Jee JG, Bae JS, Liu KH and Lee YM: A group of novel hif-1alpha inhibitors, glyceollins, blocks HIF-1alpha synthesis and decreases its stability via inhibition of the PI3K/AKT/mTOR pathway and Hsp90 binding. J Cell Physiol 230: 853-862, 2014.
19. Kim BR, Yoon K, Byun HJ, Seo SH, Lee SH and Rho SB: The anti-tumor activator sMEK1 and paclitaxel additively decrease expression of HIF-1 $\alpha$ and VEGF via mTORC1-S6K/4E-BP-dependent signaling pathways. Oncotarget 5: 6540-6551, 2014.

20. Yang Z, Luo H, Wang $\mathrm{H}$ and Hou $\mathrm{H}$ : Preparative isolation of bufalin and cinobufagin from Chinese traditional medicine Chansu. J Chromatogr Sci 46: 81-85, 2008.

21. Hu F, Han J, Zhai B, Ming X, Zhuang L, Liu Y, Pan S and Liu T: Blocking autophagy enhances the apoptosis effect of bufalin on human hepatocellular carcinoma cells through endoplasmic reticulum stress and JNK activation. Apoptosis 19: 210-223, 2014.

22. Zhang ZJ, Yang YK and Wu WZ: Bufalin attenuates the stage and metastatic potential of hepatocellular carcinoma in nude mice. J Transl Med 12: 57, 2014.

23. Zhu Z, Sun H, Ma G, Wang Z, Li E, Liu Y and Liu Y: Bufalin induces lung cancer cell apoptosis via the inhibition of PI3K/Akt pathway. Int J Mol Sci 13: 2025-2035, 2012.

24. Li M, Yu X, Guo H, Sun L, Wang A, Liu Q, Wang X and Li J: Bufalin exerts antitumor effects by inducing cell cycle arrest and triggering apoptosis in pancreatic cancer cells. Tumour Biol 35: 2461-2471, 2014.

25. Tsai SC, Lu CC, Lee CY, Lin YC, Chung JG, Kuo SC Amagaya S, Chen FN, Chen MY and Chan SF: AKT serine/ threonine protein kinase modulates bufalin-triggered intrinsic pathway of apoptosis in CAL 27 human oral cancer cells. Int J Oncol 41: 1683-1692, 2012.

26. Zhai B, Hu F, Jiang X, Xu J, Zhao D, Liu B, Pan S, Dong X Tan G, Wei Z, et al: Inhibition of Akt reverses the acquired resistance to sorafenib by switching protective autophagy to autophagic cell death in hepatocellular carcinoma. Mol Cancer Ther 13: 1589-1598, 2014.

27. Zhao D, Zhai B, He C, Tan G, Jiang X, Pan S, Dong X, Wei Z, Ma L, Qiao H, et al: Upregulation of HIF-2 $\alpha$ induced by sorafenib contributes to the resistance by activating the TGF- $\alpha / \mathrm{EGFR}$ pathway in hepatocellular carcinoma cells. Cell Signal 26: 1030-1039, 2014.

28. Meng Z, Yang P, Shen Y, Bei W, Zhang Y, Ge Y, Newman RA, Cohen L, Liu L, Thornton B, et al: Pilot study of huachansu in patients with hepatocellular carcinoma, nonsmall-cell lung cancer, or pancreatic cancer. Cancer 115: 5309-5318, 2009.

29. Dillon RL and Muller WJ: Distinct biological roles for the akt family in mammary tumor progression. Cancer Res 70: 4260-4264, 2010.

30. Burris HA III: Overcoming acquired resistance to anticancer therapy: Focus on the PI3K/AKT/mTOR pathway. Cancer Chemother Pharmacol 71: 829-842, 2013.

31. Molife LR, Yan L, Vitfell-Rasmussen J, Zernhelt AM, Sullivan DM, Cassier PA, Chen E, Biondo A, Tetteh E, Siu LL, et al: Phase 1 trial of the oral AKT inhibitor MK-2206 plus carboplatin/paclitaxel, docetaxel, or erlotinib in patients with advanced solid tumors. J Hematol Oncol 7: 1, 2014.

32. Davies BR, Greenwood H, Dudley P, Crafter C, Yu DH, Zhang J, Li J, Gao B, Ji Q, Maynard J, et al: Preclinical pharmacology of AZD5363, an inhibitor of AKT: Pharmacodynamics, antitumor activity and correlation of monotherapy activity with genetic background. Mol Cancer Ther 11: 873-887, 2012.

33. Dasari S and Tchounwou PB: Cisplatin in cancer therapy: Molecular mechanisms of action. Eur J Pharmacol 740: 364-378, 2014.

34. Stronach EA, Chen M, Maginn EN, Agarwal R, Mills GB, Wasan $\mathrm{H}$ and Gabra H: DNA-PK mediates AKT activation and apoptosis inhibition in clinically acquired platinum resistance. Neoplasia 13: 1069-1080, 2011.

35. Li M, Balch C, Montgomery JS, Jeong M, Chung JH, Yan P, Huang TH, Kim S and Nephew KP: Nephew, Integrated analysis of DNA methylation and gene expression reveals specific signaling pathways associated with platinum resistance in ovarian cancer. BMC Med Genomics 2: 34, 2009.

36. Stegeman H, Kaanders JH, Wheeler DL, van der Kogel AJ, Verheijen MM, Waaijer SJ, Iida M, Grénman R, Span PN and Bussink J: Activation of AKT by hypoxia: A potential target for hypoxic tumors of the head and neck. BMC Cancer 12: 463, 2012. 